\title{
Epoxy-Granite Properties using Indian Origin Granite
}

\author{
Kailas V. Gurav, V. M. Kale, Akash Sah
}

\begin{abstract}
Precision machine tools are expected to operate at higher machine speed to produce precise products. Hence, its structures must have high structural stiffness and high damping along with dimensional and geometrical stability. Granite is the material used for metrological and precision machine manufacturing applications. Granite is also used in some of the high accuracy machine tool manufacturing. Considering the natural properties and limitations of granite a new emerging material named Epoxy Granite is evolved. In this paper, Epoxy Granite properties using Indian Black granite are studied. In particular, the maximum load-bearing and density of epoxy granite are focussed. Also, the combination which is best suited for the applications can be easily dragged out. Density is compared with maximum load-bearing and their relation is also put forward to simplify the selection process of epoxy granite.
\end{abstract}

Keywords: Epoxy Granite, Mechanical properties, Density, Maximum bearing load, Flexural Modulus.

\section{INTRODUCTION}

Designing process of machine component involves manystages; it starts with defining functionality and performance requirement, to the testing of individual component and finally testing the complete machine. Design considerations also include the time required and cost involved to covert concept design in to a functional machine. Design methodology influences the optimization of material selection which results in an optimized combination of cost, time and functionality. Use of functionally efficient and good performing material, having lower cost can help in reducing the effective cost of the machine.

Fabricated steel structure and Cast iron are some of the conventional materials used for manufacturing structural parts of the machine (1) (2) (3). For precision machines granite is used as the main structural part, e.g. base or bed. Granite is also majorly used in metrological machine manufacturing (4) (5) (6). Good compressive strength, high thermal capacity, high level of hardness, machinability and ability to lap the surface makes it an ideal choice as a machining component. High damping capacity is an added advantage of this material, which damps the external as well machine generated vibrations.It actually helps to achieve great positional accuracy and repeatability that results in the least tolerance parts and accurate measurements.

Revised Manuscript Received on February 05, 2020.

* Correspondence Author

Kailas V. Gurav*, Rajarshi Shahu College of Engineering, Department of Mechanical, Pune, India. E-mail: designhead@accurategauging.com

V. M. Kale, Prof. Department of Mechanical, Indira College of Engg. And Management Pune, India. E-mail: vinayak.kale@indiraicem.ac.in

Akash Sah, PG Scholar, Bharati Vidyapeeth Deemed University, College of Engineering, Pune, India. E-mail: akashsah94@gmail.com

(C) The Authors. Published by Blue Eyes Intelligence Engineering and Sciences Publication (BEIESP). This is an open access article under the CC BY-NC-ND license (http://creativecommons.org/licenses/by-nc-nd/4.0/)
With all these advantage points, come some limitations of granite.Brittleness, availability of continuous large pieces in the desired shape, and the high skill requirement for processing of the material are the few to be noted. Considering both its good properties aling with its limitations, an entirelynew material named epoxy granite is explored (5) (3) (7).

Epoxy Granite is a composite material having aggregate crushed granite particles mixed with formulated epoxy resin. Once mixed, the mixture is cast in a mould and cured at room temperature. Epoxy granite is a low-density material, owing very good dynamic properties due to which it is the most preferred material in the machine tool industry. The density of granite varies from $2.5 \times 10^{3} \mathrm{~kg} / \mathrm{m}^{3}$ to $3 \times 10^{3} \mathrm{~kg} / \mathrm{m}^{3}$ whereas the density of epoxy granite varies from $2.45 \times 10^{3}$ $\mathrm{kg} / \mathrm{m}^{3}$ to $2.8 \times 10^{3} \mathrm{~kg} / \mathrm{m}^{3}$. Here the variation in the density is caused due to aggregate sizes, shapes and compaction.

A recent study on epoxy granite is about finding the different material properties like its compressive strength, flexural strength, modulus of elasticity, coefficient of thermal expansion, damping capacity, required for machining. (8) (9) (10). Density is a property which decides the total weight of the system, and important from dynamic forces, transport, cost, deformation and self-weight point of views. Generally, lower density with higher stiffness is preferred for designing the structural part of the machine. Young's modulus plays a significant role against the deformation, higher the modulus of elasticity, better is the stiffness. When the loads are in a tensile manner, tensile strength is considered. The structural component of a machine e.g.its base, sustains complete machine loads, here, we use 'compressive strength'for this calculation, whereas, 'flexural strength' is considered in the case of bending loads. Rotatory motion, linear motion and uneven loads generate vibrations in the machine but the damping properties of machine components can damp these vibrations. In porous materials, such as granite, water absorption affects the material properties. Surface Finish, which is the deviation of the surface against the true plane, can be achieved in epoxy-granite composites. And, as a part of the thermal properties, coefficient of thermal expansion is studied.

In the world market, there are nearly 300 varieties of granite, out of which India supplies about 200 varieties (11). Out of these, prime varieties represent a wide spectrum of colour, texture, and structure. The major production of raw as well as processed granite is generally obtained from the southern region of India. Indian black granite, black galaxy, is one of the granites, being used in Metrology Industry. This granite holds certain mechanical, physical and chemical properties suitable for machines (1) (12). 


\section{Epoxy-Granite Properties using Indian Origin Granite}

A further study and analysis of the properties of epoxy granite using these materials is required.

In the following paper, the study of Epoxy Granite properties using Indian black granite is carried out. Waste granite material from one of the metrological industries is used to prepare Epoxy-Granite specimens. Here, the attempt is to find out the maximum density of the dry mixture of different granular sizes of granite in different weight combinations. It also aims to simplify the selection of granite granular weight combinations to maximize the density and subsequent material properties. The study focuses on investigating some of the prime properties like density, compressive strength, flexural strength, damping factor in this context.

\section{EXPERIMENTATION}

\subsection{Specimen preparation}

Indian Black Granite with compressive strength of 2700 $\mathrm{kg} / \mathrm{cm}^{2}$ to $3000 \mathrm{~kg} / \mathrm{cm}^{2}$ is selected to prepare granular. Granular particles are segregated into 4 different aggregate sizes of granite i.e., $0.1-0.3 \mathrm{~mm}, 1-3 \mathrm{~mm}, 4-8 \mathrm{~mm}, 8-11 \mathrm{~mm}$. A theoretical study has been conducted using 3D cad modelling with spherical shapes to decide the different size and weight percentage in combination as $40-30-20-10 \%, 30-$ 25-25-20\%, 20-20-30-30\%, 10-15-35-40\% respectively. Four different epoxy percentages by weight - 8\%, 12\%, $16 \%, 20 \%$ and two different vibrating frequencies - $45 \mathrm{~Hz}$ and $60 \mathrm{~Hz}$ are taken for experimentation purpose. Hence, variables under consideration are different aggregate sizes of granular granite and their percent aggregate combination by weight, different epoxy percentages by weight and different vibrating frequencies. Total 32 specimens were prepared by considering different combinations, 12 of which are shown in fig. 2.

According to ASTM - C35, a test specimen size of $300 \times 50 \times 50 \mathrm{~mm}$ is decided. The vibration table [fig. 1] is specially manufactured to conduct the compaction test of granular weight percentage vs density and to obtain the epoxy granite specimens [fig. 2] by providing different vibration frequency.

Initially, several iterative attempts were made to gain the maximum density and selective combinations were taken. As the outcome of compaction test, it was observed that maximum density is not achieved with individual granule, even though the granular size is 0.1 to $0.3 \mathrm{~mm}$, granular combination of $0.1-0.2+12-14 \mathrm{~mm}$ grain size gives maximum density, and combination of $12-14 \mathrm{~mm}, 8-11 \mathrm{~mm}$, 4-8 $\mathrm{mm}$ and $0.1-0.3 \mathrm{~mm}$ gives a secondary maximum weight of mixture. Compaction test outcomes were used to decide weight percentage as $40-30-20-10 \%$, 30-25-25-20\%, 20-2030-30\%, 10-15-35-40\% respectively.

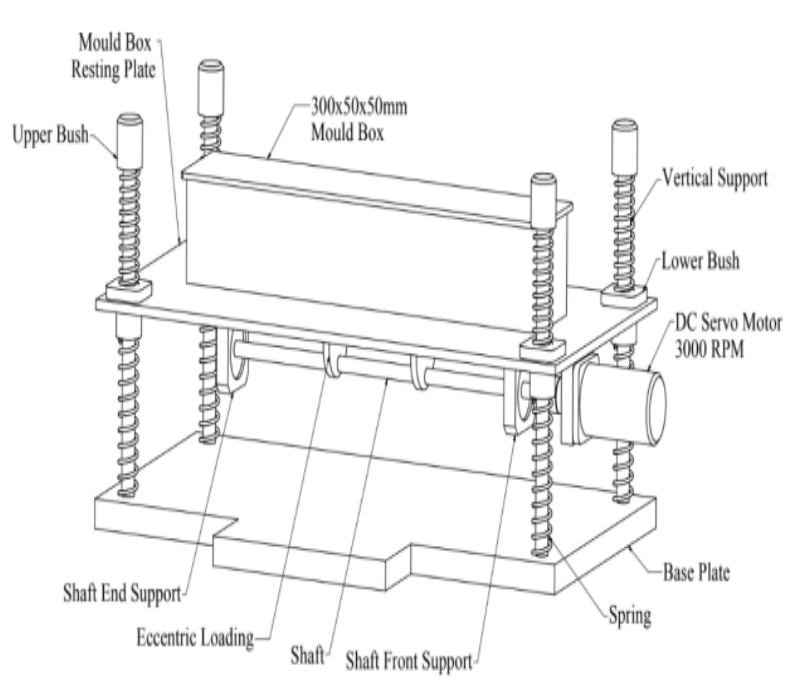

Figure 1: Mould box with vibration table

\subsection{Epoxy-granite specimen moulding/casting}

Granular granite, resin and hardener were taken by weight percentage and mixed thoroughly for 10-12 minutes, on the other side, mould box was clamped on a vibration table and separating agent was applied on inside walls of mould box for easy removal of cast afterwards. The mixture of epoxy and granular granite is poured in a mould box, and is kept under constant vibrations for about 10-15 minutes at a predecided vibration frequency. Mould box with mould is kept at normal room temp for $24 \mathrm{hrs}$ and after $24 \mathrm{hrs}$ the mould box was disassembled and the specimen was taken out for further inspection.

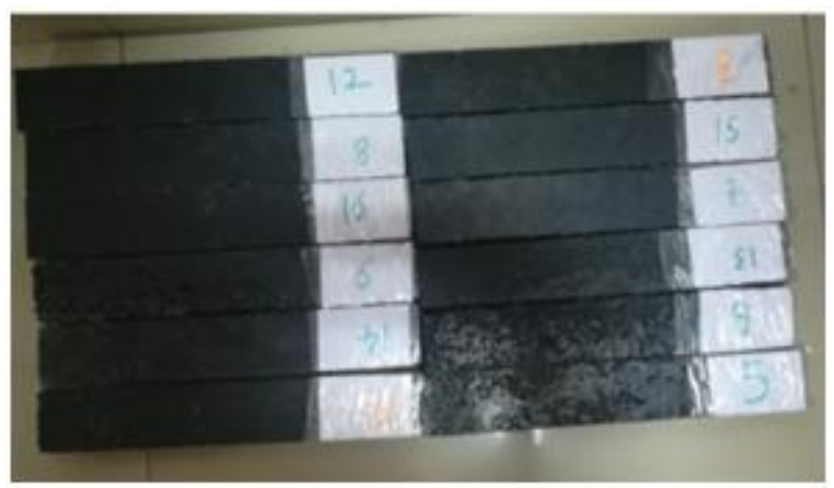

Figure 2: Specimens prepared by different combinations of epoxy and granite

\section{INSPECTION AND TESTING}

Dimensional measurement and weight of all 32 specimens were inspected and density of each specimen was calculated. A further study was conducted to find out the relation of a different combination of granular granite and its density.

$$
\text { Density }=\frac{W}{V} \mathrm{gm} / \mathrm{cm}^{3}
$$

$\mathrm{w}=$ weight of the specimen, gm

$\mathrm{v}=$ volume of the specimen, $\mathrm{cm}^{3}$

Flexural testing, using the 3-point method is used for measuring maximum load-bearing and flexural modulus.
Published By:

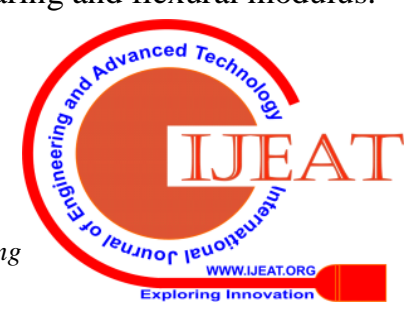


ASTM C580-02, a widely used UTM was chosen to conduct different tests.

ASTM C580-02 covered the determination of flexural strength and modulus of elasticity in flexure of cured chemical-resistant materials in the form of moulded rectangular beams. These materials include mortars, brick and tile grouts, structural grouts, machinery grouts, and polymer concretes. These materials shall be based on resin, silicate, silica, or sulphur binders. This test is generally applicable to rigid and semi-rigid materials; therefore, this is used as a guide during experimentation.

\section{RESULTS}

The results obtained are put into a graphical form and compared with their respective variables to find out the best combination for getting the desired property.

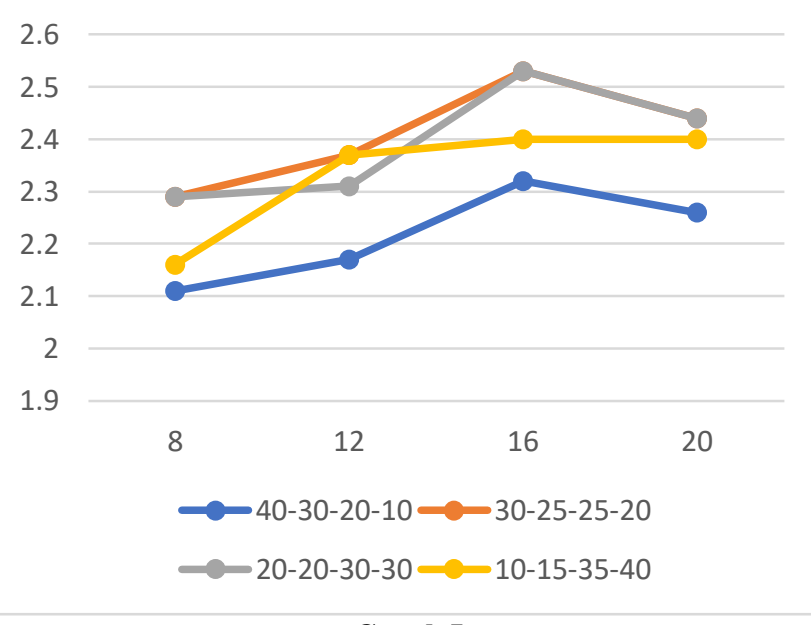

Graph I

A graph for density vs. epoxy percentage [Graph I] is plotted and 4 lines of different colours represent aggregate size combination, the graph clearly indicates that for all the combinations, at $16 \%$ epoxy concentration, specimens show greater density. So, it can be concluded that $16 \%$ epoxy gives greater density than any other epoxy percentage in the mentioned combinations. Thus, graph I is clearly indicating that density is directly proportional to the Max load.

Graph for density vs aggregate size combination [Graph II] is plotted and 4 lines represent epoxy percentages, graph is showing that $30-25-25-20$ and $20-20-30-30$ combinations are giving more denser specimen but particularly in case of $12 \%$ epoxy at 20-20-30-30 combination, it is going downward which makes 30-25-25-20 combination superior. So, we can conclude that to get the denser specimen we can select 30-25-25-20 combination.

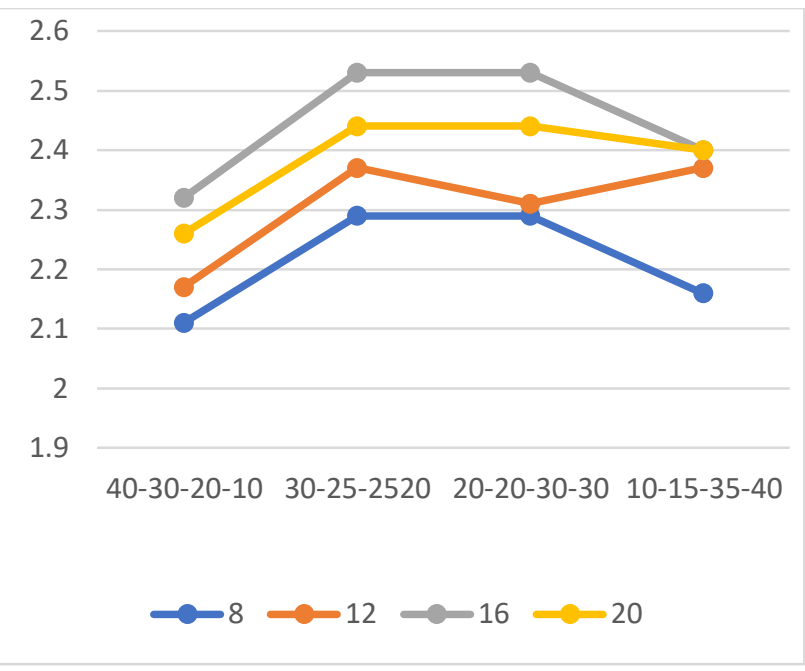

Graph II

Altogether, a specimen of 16\% epoxy with 30-25-25-10 combination gives the best density among all the specimens.

From the application point of view, if density is playing a vital role and is responsible for many other parameters, this reference or experimentation is enough, as well as, provides a guideline on how to find the best epoxy granite for loading applications particularly.

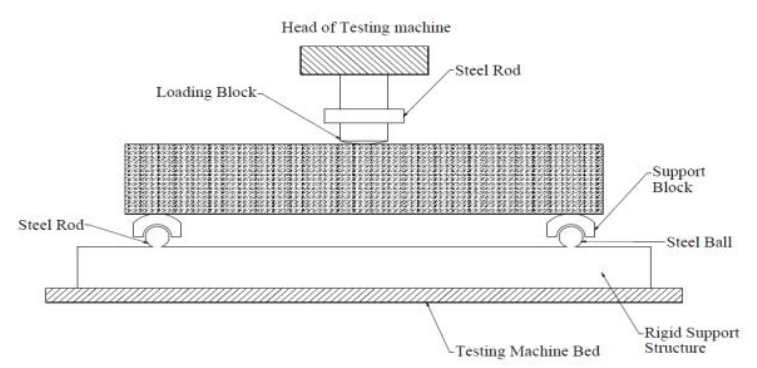

Figure 3: Flexural testing set up

Flexural Strength checking, in total 12 specimens were selected for this experimentation covering all the ranges of granite-epoxy combinations available.

Table 1: Density and max load of selected epoxy granites specimen

\begin{tabular}{|l|l|l|}
\hline Specimen No. & $\begin{array}{l}\text { Density } \\
\left(\mathrm{gm} / \mathrm{cm}^{3}\right)\end{array}$ & $\begin{array}{l}\text { Max load } \\
(\mathrm{kN})\end{array}$ \\
\hline 1 & 2.33 & 4.8 \\
\hline 2 & 2.29 & 2.73 \\
\hline 3 & 2.37 & 6.1 \\
\hline 4 & 2.54 & 7.95 \\
\hline 5 & 2.44 & 8 \\
\hline 6 & 2.29 & 3.99 \\
\hline 7 & 2.3 & 4.35 \\
\hline 8 & 2.44 & 7.14 \\
\hline 9 & 2.16 & 1.86 \\
\hline 10 & 2.37 & 4.7 \\
\hline 11 & 2.4 & 7.1 \\
\hline 12 & 2.4 & 7.1 \\
\hline
\end{tabular}




\section{Epoxy-Granite Properties using Indian Origin Granite}

By plotting the results into a graphical form, Maximum load vs density, we can observe that, for density value 2.54 $\mathrm{gm} / \mathrm{mm} 3$, which is maximum among all it shows the maximum load capacity of $7.95 \mathrm{kN}$.

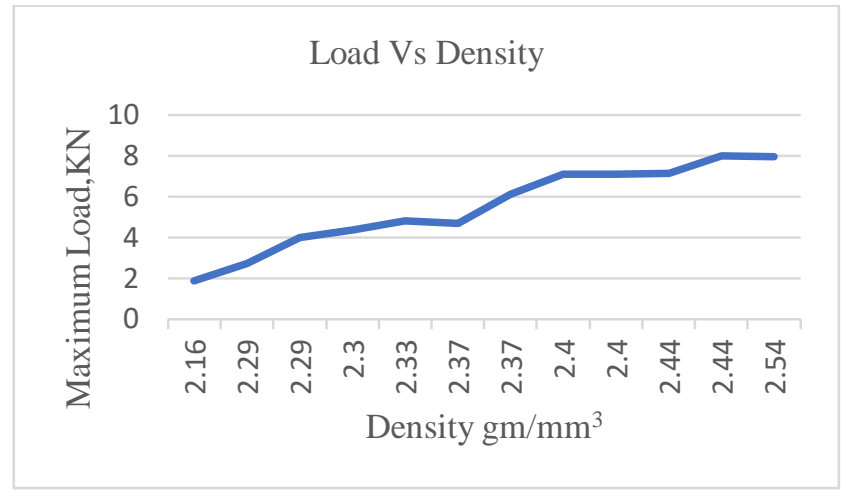

\section{Graph III}

Hence, sample no. 4 (Aggregate combination 30,25,25,20; Epoxy percentage - 16\%; Vibrating frequency $60 \mathrm{~Hz}$; Epoxy type - E1) is taking maximum load. Least density which is $2.16 \mathrm{gm} / \mathrm{mm}^{3}$ of sample no. 9 (Aggregate combination - 10,15,35,40; Epoxy percentage - 8; Vibrating frequency - 60; Epoxy type - E1) has least max load of 1.86 $\mathrm{kN}$.

Hence, from the results and graph, it can be observed that density has a direct relation with maximum load and density is directly proportional to the maximum load.

Also, modulus of rupture is directly proportional to maximum load. Hence, density is directly proportional to the modulus of rupture, as shown below:

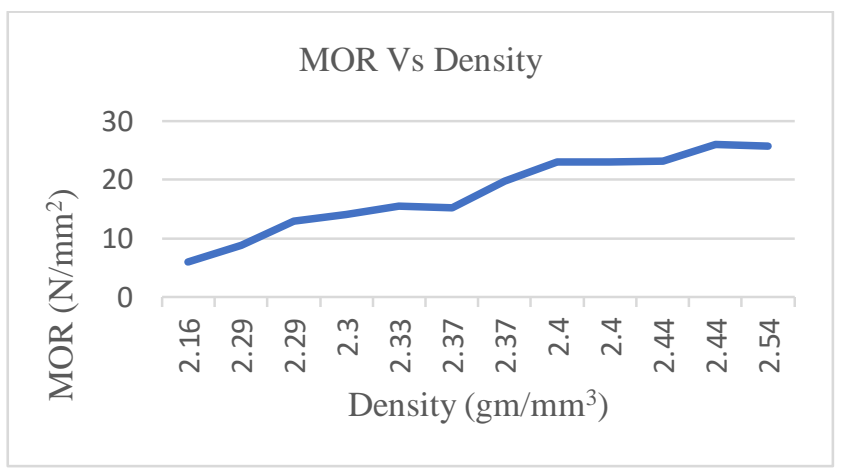

$$
\begin{gathered}
\text { Graph IV } \\
M O R=\frac{3 * F * L}{2 * b * d^{2}}
\end{gathered}
$$

$\mathrm{MOR}=$ modulus of rupture, $\mathrm{N} / \mathrm{mm} 2$

$\mathrm{F}=$ load at a given point on the load deflection curve, $\mathrm{N}$

$\mathrm{L}=$ Support span, $\mathrm{mm}$

$\mathrm{b}=$ Width of test beam, mm

$\mathrm{d}=$ Depth or thickness of tested beam, mm

\section{CONCLUSION}

1. Compaction technique can be used to maximize the density of Epoxy-Granite.

2. Maximum Density results into maximum flexural strength and max load carrying capacity.
3. Competitive Epoxy Granite Properties can be achieved by using Indian Black Granite.

\section{REFERENCES}

1. Hans-Christian; Materials in machine tool structures 2015; CIRP Annals - Manufacturing Techno.

2. M Rahman, M. A. Mansur and S. H. Lau. s.l.; Tool wear study in lathe made of cementitious material; Journal of Material Processing Technology, 2001, Vol. 113, pp. 317-321.

3. Norbert Kepczak, WitoldPawlowski and WiselawBlazejewski. s.l.; The Study of The Mechanical Properties of The Mineral Cast Material; Archives of Mechanical Technology and Automation, 2014, Vol. 34, pp. 25-32.

4. K. Erkorkmaz, J.M. Gorniak and D.J. Gordon. s.l.; Precision machine tool $\mathrm{X}-\mathrm{Y}$ stage utilizing a planar air bearing arrangement; CIRP Annals - Manufacturing Technology, 2010, Vol. 59, pp. 425-428.

5. Mckeown, P A.; Epoxy granite: a structural material for precision machines; Precision Engineering 1979, pp.227-229., pp. 1-2.

6. Bruin, W. de. 2, s.l.; Dimensional Stability of Materials for Metrological and Structural Applications; Annals of the CIRP, 1982, Vol. 31.

7. Selvakumar, A and Mohanram, P.V. s.l.; Analysis of Alternative Composite Material for High Speed Precision Machine Took Strctures; Annals of Faculty Engineering Hunedoara-International Journal of Engineering, 2012, pp. 95-98. ISSN 1584-2665.

8. Hyun Surk Kim, KyuYcol Park and Dal Gil Lee. s.l.; A study on the epoxy resin concrete for the ultra-precision machine tool bed; Journal of Materials Processing Technology, 1995, Vol. 48, pp. 649-655.

9. N.Mahendrakumar, S.Syathabuthakeer and P. V.Mohanram. s.l.; Study of Alternative Structural Materials for Machine Tools; 5th International \& 26th All India Manufacturing Technology, Design and Research Conference, 2014, pp. 645-1 to 645-6.

10. Piratelli-Filho, Antonio and Fank, Shimabukuro. Characterization of Compressive Strength of Grsnite-Epoxy Composite Using Design of Experiments. s.l.; Materials Research,Vol 11,No 4,399-404, 2008.

11. INDIA, Govt. Indian Minerals Year Book. 2013.

12. Dwived, R D and Goel, R K. Thermo-mechanical properties of Indian and other granites. s.l.; International Journal of Rock Mechanics \& Mining Sciences, 2008.

13. M. Vijayalakshmi, A.S.S. Sekar and G. Ganesh prabhu. s.l.; Strength and durability properties of concrete made with granite industry waste; Construction and Building Materials, 2013, Vol. 46, pp. 1-7.

14. Dinsdale, J. 4, s.l.; Precision engineering aspects of record player design; PRECISION ENGINEERING, 1983, Vol. 5.

15. Kushnir, Emmanuil F., Patel, Mahendra R. and Terrence M. Sheehan Hardinge Inc. s.l.; Material Considerations in Optimization of Machine Tool Structure; Proceedings of 2001 ASME International Mechanical Engineering Congress and Exposition, Elmira, NY. 1116 November 2001.

16. Orak, Sezan. s.l.; Investigation of vibration damping on polymer concrete with polyester resin; Cement and Concrete Research, 2000 Vol. 30, pp. 171-174.

17. H. V. Ramakrishna, S. Padma Priya, S. K. Rai. s.l.; Flexural, Compression, Chemical Resistance, and Morphology Studies on Granite Powder-Filled Epoxy and Acrylonitrile Butadiene StyreneToughened Epoxy Matrices; Journal of Applied Polymer Science, 2007, Vol. 104, pp. 171-177.

18. A Selvakumar, K Ganesan and PV Mohanram. s.l.; Dynamic analysis on fabricated mineral cast lathe bed; Journal of Engineering Manufacture, 2012.

19. Banerjee, K.P. Roysarkar and M.K.; Designing Machine Tool Structures With Epoxy Concrete.

20. Hartel, M. Weck and R. 3, s.l.; Design, manufacture and testing of precision machines with essential polymer concrete components; PRECISION ENGINEERING, 1985, Vol. 7.

21. Dukovski, G. Vrtanoski and V. s.l.; Design of polimer concrete main spindle housing for cnc lathe; 13th International Scientific Conference on Achievements in Mechanical and Materials Engineering, 2005, pp. 695-698.

22. Lee, Jung Do Suh and Dai Gil. s.l.; Design and manufacture of hybrid polymer concrete bed for high-speed CNC milling machine; Springer; Int J Mech Mater Des, 2008, Vol. 4, pp. 113-121.

23. Pawlowski, Norbert Kepczak and Witold. 4, s.l.; Application of Mineral Casting for Machine Tools Beds; Mechanics and Mechanical Engineering, 2013, Vol. 17, pp. 285-289. 